\title{
EXERCÍCIO DO PODER DIANTE DA COMPLEXIDADE DAS RELAÇÕES NO ESPAÇO MÉDICO-HOSPITALAR E DE ENFERMAGEM*
}

Ivete Palmira Sanson Zagonel ${ }^{1}$

\begin{abstract}
RESUMO: Pretende-se realizar uma reflexão sobre o exercício dopoder disciplinar no espaço médico-hospitalar e de Enfermagem, através dos espaços históricos do surgimento da Medicina, do Hospital e da Enfermagem. Este propósito evidencia a evolução do enfermeiro como profissional, sua submissão ao saber médico e institucional, o valor social atribuído à prática de Enfermagem estando ligada intimamente ao modo de vida conventual e de dominância. Neste contexto a Enfermagem luta para firmar-se como ciência, tentando desfazer-se de uma prática ligada ao fazer para tornarse científica. Resgata a importância Enfermagem voltar-se ao cliente através do cuidado, sua razão de ser.

DESCRITORES: História da Enfermagem; Hospitais; Poder (psicologia); Disciplina no trabalho; Relações interprofissionais.
\end{abstract}

\section{POWER EXERCISE FACING THE COMPLEXITY OF RELATIONS IN MEDICAL- HOSPITAL AND NURSING SETTINGS}

\begin{abstract}
This purpose is a thought - provoking study on the exercise of disciplinary power in medical - hospital and nursing settings, historically focusing on the onset of medicine, hospitals and nursing. This purpose evidences the evolution of the nurse as a professional, his/ her submission to institucional or medical knowledge and the social appraisal attributed to nursing practice wich is closely connected with a cnventual, submissive way ofliving. In this context, nursing has strived to obtain a scientific status andhas tried to eliminate its solelyu practical nature. I have re-apprehended the importance of nursing centered on client's care, its ultimate goal.
\end{abstract}

DESCRIPTORS: History of nursing; Hospitals; Power (psychology); Employee discipline; Intrerprofessional relations.

\footnotetext{
* Trabalho apresentado como requisito final da disciplina de Filosofia da Ciência e Saúde II - Curso de Doutorado em Filosofia da Enfermagem da Universidade Federal Santa Catarina-UFSC - 1995.

Enfermeira. Professora Adjunta do Departamento de Enfermagem da Universidade Federal do Paraná-UFPR. Doutoranda do curso de Doutorado em Filosofia de Enfermagem da UFSC. Membro do programa Intgrado de Pesquisa Cuidando e Confortando.
} 


\section{INTRODUÇÃO}

Na luta pelo estabelecimento de melhores condições de vidas para todos, tem havido inegável avanço. A Constituição brasileira de 1988 registra este avanço de modo bastante expressivo, proclamando a existência do direito À saúde como um dos direitos fundamentais da pessoa humana. A lei maior do país qualifica os serviços de saúde como de relevância pública e prevê a participação necessária de setores públicos de todos os níveis, ao lado de organizações sociais e de toda a comunidade. O artigo 194 da Constituição brasileira declara que "a seguridade social compreende um conjunto integrado de ações de iniciativa dos Poderes Públicos e da sociedade, destinadas a assegurar os direitos relativos à saúde, à previdência, e à assistência social" (Carvalho, Santos, 1992, p. 24). Esses direitos assegurados na Constituição surgem de idéias e estratégias amplamente discutidas, especialmente na VIII Conferência Nacional de Saúde, em que se delineou um conjunto de princípios e diretrizes, no sentido de assegurar jurídicfa e institucionalmente o Sistema Único de Saúde.

A Lei Orgânica de Saúde de 1990 sustenta-se em cinco princípios básicos: universalização do atendiumento, eqüidade no atendimento, integralidade das ações de saúde, descentralização e controle social. Estes são os requisitos para que o Sistema Único de Saúde (SUS) seja efetivamente implantado. Porém se observa que o avanço do SUS tem sido lento, pouco se tem dirigido na dimensão operacional da adequada prestação de serviços e resolução de problemas na área de saúde. Desenvolver a operacionalidade deste sistema é grande desafio, principalmente no sentido de dar a dimensão práticas a essas metas, para transformar a realidade cotidiana. Na construção de SUS há necessidade de mobilizar forças e apontar caminhos para o alcance do objetivo maior de melhoria da saúde para todos.

Cumpre passar das palavras, faladas ou escritas na lei, às ações. Este trabalho começa por apontar alguns aspectos históricos acerca do surgimento do hospital, da Medicina e da Enfermager, com algumas reflexões sobre a atuação dos profissionais da Enfermagem, cfom ênfase nas relações de poder que permeiam oprocesso de cuidado do cliente.

Essas reflexões e abordagens servem para fornecer subsídios às ações que vão ser efetivamente implemetadas, com base na lei orgânica de Saúde vigente em nosso país, objetivando garantir o espaço próprio de atuação do enfermeiro diante da equipe de saúde, com vistas à melhoria da saúde.

\section{RAZÃO DE SER DA ENFERMAGEM}

Nestes vários anos transcorridos de desenvolvimento profissional, os enfermeiros estão sentindo uma mudança básica, isto é, a reforma de um ideal filosófico, que lançou a Enfermagem como uma ciência. Somente com o advento do modernismo e o nascimento da Enfermagem moderna, no final do século XIX, é que a ciência de Enfermagem tem enfrentado uma riqueza de possibilidades para o desenvolvimento do conhecimento. A Enfermagem está abraçando uma definição abrangente, que emprega várias fontes chaves para o desenvolvimento do conhecimento de Enfermagem. Essas fontes derivam, conforme
Reed (1995), de atividades empíricas, conceituais e práticas dos enfermeiros, porém tem sido consideradas independentes pela maior parte dos enfermeiros do século XX.

Para o desenvolvimento de umja Enfermagem para o século XXI, há necessidade de ligar o fenômeno ao objeto, ligar conceitos empíricos com conceitos teóricos, como meio de reformar e reafirmar as abordagens de Enfermagem para o desenvolvimento do conhecimento.

Ao longo da estória da Enfermagem, o método da ciência tem mudado. Nightingale (1859), empirista tradicional, restringiu sua teoria a processos observáveis, tendia a generalizwr por analogia. Este conhecimento, gerado por analogia, deixou uma lacuna entre o evento empírico e a explicação teórica. Surge então o trabalho de Peplau. Entre Nightingale e Peplau houve um hiato de meio século no trabalho científico de Enfermagem, que alterou métodos de desenvolvimento do conhecimento. A lógica hipotético - dedutiva emergia, ligando o teórico ao empírico. Peplau ajudou a transformar a Enfermagem de uma ciência do fazer para uma ciência do saber, criando uma teoria de relações interpessoais; incorporou prática e teoria em suas idéias de pesquisa. $\mathrm{O}$ seu processo de pesquisa começou na prática, espiralando e abstrído de outras teorias para explicar o fenômeno; retornou à prática para examinar o novo conhecimento à luz de experiências e realidade da prática (REED, 1995).

O pós-modernismo tem estimulado maior consciência, entre os enfermeiros, da cultura da prática, como uma fonte de fundamental significado a respeito do objeto dessa prática: saúde e cura dos seres humanos. No século XIX, Florence Nightingale conceitualizou a Enfermagem em termos de ambiente saudável e focalizou a habilidade do Enfermeiro em auxiliar o potencial de cura dos clientes. A saúde é central à Enfermagem, o que se demonstra por vários teoristas, metateoristas e estudiosos de Enfermagem. O grande questionamento é em relação à centralidade do conceito de saúde na Enfermagem. Este conceito é diferente para as outras disciplinas? Porque a Enfermagem considera seu foco central?

Meleis (1992, p. 40) aborda com muita propriedade os vários níveis de significado da experiência saúde doença por meio de várias visões: na visão científica, “os indicadores médicos, materiais e molecularesda presença ou ausência de doença. Nesta visão a tarefa é reprimir sintomas, remover a causa ou substituir a parte adoentada." Na visão psicológica, "as estruturas de personalidade sãorelacionadas com a saúde e a doença." $\mathrm{Na}$ visão preventiva, " fala a linguagem da avaliação de riscos da saúde ..., controle da saúde pelos próprios clientes”. Na visão cultural, social e política, "aborda o papel do ambiente tanto no processo da doença como no da saúde”. Na visão metafórica e simbólica, "os significados de saúde são encontrados na intuição e no simbolismo". Na visão de espaço, tempo e energia, " a pessoa é conceitualizada como um organismo bioenergético". Como se percebe todas essas visões englobam os significados de saúde que são interativos, sendo envolvidos poruma abordagem holística. O que então realmente delimita o território da Enfermagem?

Para a Enfermagem chegar a esse patamar de formar-se como ciência, às portas do século XXI, necessitou conviver comtodas esta diversidade e multiplicidade de visões que fizeram 
a sua história. Por trás deste esforço está embutido todo um poder disciplinar a que esteve e ainda está submetida. Este poder se calcou no nascimento do hospital e da Medicina, que mantiveram uma imposição de situações, até que chegasse ao estágio atual. É por meio do enfoque histórico que demonstro a evolução da disciplina de Enfermagem, sua submissão ao saber médico e institucional, o valor social atribuído à prática de Enfermagem que está intimamente ligado ao modo de vida conventual e dominação médica, sua valorização e desvalorização.

\section{O PODER E NATUREZA DO hOSPITAL E DA MEDICINA}

Em torno de 1780 aparece o hospital com um consciência que este pode e deve ser instrumento de cura, instrumento terapêutico (FOUCAULT, 1992). Para que a experiência clínica fosse possível como forma de conhecimento, foi preciso toda uma reorganização do campo hospitalar, uma nova definição do estatuto do doente na sociedade e a instauração de uma determinada relação entre a assistência e a experiência. Surgem nessa época, conforme Foucault (1994), as visitas e observações sistemáticas e comparadas dos hospitais. As visitas foram realizadas por Howard, inglês, que não era médico, e por Tenon médico francês, que visitaram vários hospitais da Europa. $\mathrm{O}$ objetivo dessas viagens era investigar a situação dos hospitais, para então definir um programa de reforma e reconstrução. Esses inquéritos não visavam a detalhar a parte arquitetônica e externa dos hospitais, mas a traçar um perfil da estrutura interna, como o levantamento do número de doentes por hospital, o número de leitos, a área útil do hospital, condições das salas e taxa de mortalidade e cura. Surge, assim, um novo conceito de hospital, em que se estabelece a relação com as patologias e o espaço. Tenon verifica que as parturientes colocadas no andar acima dos feridos tinham a taxa de mortalidade aumentada.

Até a Idade Média o hospital na Europa não era considerado um meio de cura, não era instituição médica, e a Medicina não era uma prática hospitalar. O hospital era uma instituição de assistência aos pobres, como também de exclusão e separação. A inovação do século XVIII foi a introdução de uma Medicina hospitalar ou um hospital médico-terapêutico. Até o século XVIII a personagem principal do hospital não era o cliente que precisava de cura, mas o pobre que estava morrendo, este necessitava de assistência espiritual e material (Focault, 1990). O hospital, então, exercia uma função na transição entre a vida e a morte, unida à função de separar os indivíduos perigosos (pobres, doentes), do restante da população. Os enfermos eram pobres, loucos, prostitutas, os incuráveis, os epilépticos, as crianças abandonadas, os agonizantes, os que haviam sofrido amputações, os que morriam de fome, todos eram colocados dentro da maior desordem e confusão, sem levar em conta o sexo ou idade, onde vários indivíduos ocupavam o mesmo leito.

Até meados do século XVIII, o hospital e a Medicina permaneceram independentes. A transformação se deu considerando um primeiro aspecto que era a anulação dos efeitos negativos do hospital, as suas desordens. (Focault 1992) chama de desordens as doenças que o hospital pode suscitar nas pessoas internadas e espalhar pela cidade, como também a desordem econômica e social. A primeira grande organização hospitalar da Europa ocorreu no século XVIII, nos hospitais marítimos e militares. O hospital marítimo era considerado um lugar de desordem econômica, pois o traficante, fingindo estar doente, era levado ao hospital e escondia objetos da alfândega. Esta prática transformava os hospitais em lugares de tráfico intenso. Surge uma regulamentação dos hospitais, não com a intenção de transformá-los em instrumentos de cura, mas para organizar a desordem econômica.

Com o surgimento do fuzil no final do século XVIII, o exército torna-se mais técnico e começa a investir em treinamento dos soldados. Como este investimento era caro, os soldados eram protegidos para que a doença não os fizesse morrer. Para conseguir tal intento, os hospitais marítimos e militares foram reordenados a partir de uma tecnologia política, chamada "disciplina", que visava a controlar os homens, melhorar ao máximo o efeito útil de seu trabalho e sua atividade, graças a um sistema de poder (Focault, 1992). A origem do hospital médico está, portanto, ligada ao disciplinamento do espaço hospitalar e também ao deslocamento da intervenção médica, ou seja, não mais dirigida à doença mas ao que a circunda: o ar, a água, a temperatura ambiente, o regime, a alimentação, etc... Essa disciplina hospitalar visa à individualização do doente, bem como a sua distribuição em espaço em que possa ser vigiado, onde será registrado o que acontece, com a finalidade de transformar o hospital em instrumento de função terapêutica.

No final do século XVIII, é o espaço um ponto fundamental para o hospital; este deveria estar ligado aos aspectos sanitários da cidade, bem como aparece a distribuição de espaço no interior do hospital: este seria modificável de acordo com o doente, a doença e sua evolução; estabelece-se um doente por leito. A isto Focault (1992, p.109) chama de espaço individualizado da existência, a estrutura do hospital, diz ele, deve "ser fator e instrumento de cura".

Nessa mesma época surge a idéia de que o hospital era lugar propício ao estudo e à comparação de casos. O hospital chegava ao nível de estabelecimento educativo e, depois no início do século XIX, como lugar de cura. Ao longo da época clássica, a prática clínica se vai transformando com a reorganização dos hospitais como espaço clínico. O corpo humano é sede das doenças; as doenças são entidades patológicas. Foi na Inglaterra onde mais se avançou na organização dos problemas de saúde pública, diante do crescimento urbano e dos problemas do trabalho industrial (LUZ, 1988). Um fator fundamental no desenvolvimento da saúde pública foi a política econômica e social. O Estado tinha interesse em ter o maior número de súditos saudáveis. O pobre devia ter um emprego. Para auxiliar os indigentes surge a Lei dos Pobres elizabetana de 1601, (reformulada em 1834); cada paróquia se responsabilizava por seus pobres; estes, trabalhando, contribuíam para a expansão da indústria (ROSEN, 1979).

A França em 1789 vê nascer a superposição do poder revolucionário no poder médico. A Medicina explora o corpo do paciente, em busca de localizações precisas de doença. Surge a classificação das doenças (nosologia). Nasce a clínica. O hospital muda de função, não serve mais de depósito de doentes cuidados por religiosos. Durante a Revolução Francesa surge a concepção 
da relação política entre saúde e sociedade: a doença pode ser erradicada pela recuperação da saúde do corpo social (SCILIAR, 1987).

Focault (1994, p.66) escreve que antes da civilização, os povos só tinham as doenças mais simples e mais necessárias. À medida que se ascende na ordem das condições é que a rede social se fecha em torno dos indivíduos, a saúde parece diminuir gradativamente, as doenças se diversificam e se combinam, seu número já é grande. $\mathrm{O}$ contato com outros doentes altera a natureza da doença, e a torna mais difícil. Complementa fazendo a diferenciação de que

nos hospitais se encontram indivíduos que são indiferentemente portadores de uma doença qualquer... $\mathrm{Na}$ clínica, se encontram doenças cujo portador é indiferente: o que está presente é a doença no corpo... No hospital, o doente é sujeito de sua doença, o objeto transitório de que ela se apropriou.

Durante a última década do século XIX as normas e os tipos se tornaram os critérios fundamentais do diagnóstico e da terapêutica. A doença, enquanto desvio de uma norma, tornava legítima a intervenção médica e fornecia orientação para a terapia. A elaboração da doença, como a do corpo doente é fruto de uma história de cerca de três séculos, que explica por que no século XIX a disciplina nas doenças se torna ciência da sociedade (sociologia).

A Medicina pode ser considerada uma disciplina social, conforme Luz (1988, p.5), pelos seus objetos de discurso que tratam:

os corpos humanos, decompostos em elementos constituintes; o funcionamento e a desagregação desses elementos; as relações dos seres humanos com estes corpos; as mentes humanas, os sentimentos humanos; a sexualidade humana; o sofrimento humano; a morte humana.

Refere ainda que todos esses aspectos do viver e do sofrer humanos têm sido, ao longo da história, campo de objetivações da Medicina. AMedicina ordenou em categorias a doença e morte, normalidade e patologia, equilíbrio e desvio, com profundas repercussões sociais. É também considerada disciplina da natureza ou natural, ciência do homem; os médicos clínicos a consideram como a arte de salvar vidas humanas da doença e da morte. A Medicina social é a relação entre a doença e a sociedade.

Roberto Machado, ao comentar o livro de Luz (1988), refere que a Medicina é racionalista e mecanicista, pois assim como as ciências sociais do século XIX, a Medicina também herda da biologia um modelo explicativo e organicista. Há um deslocamento epistemológico desde o Renascimento, de uma arte de curar indivíduos doentes para uma disciplina das doenças. A Medicina é a grande aliada do homem no sentido de combater o mal, externo ou interno, e une-se então ao medicamento para vencer esta batalha, para derrotar a doença. No século XIX é que o uso de substâncias as mais variadas são utilizadas nos doentes. O medicamento é forma de intervenção médica, assim como a cirurgia; esta conhecia o corpo humano a partir de intervenções nesse corpo (LUZ, 1988).

Para estabelecer esta cientificidade da Medicina, surgem no Brasil escolas para a formação de médicos e cirurgiões. Em 1829 um grupo de médicos funda no Rio de Janeiro a Sociedade de Medicina do Rio de Janeiro com o objetivo de tratar dos interesses médico-sociais e do ensino da Medicina, sob os auspícios do governo. O saber médico, então, explicava a doença como determinada pelo meio ambiente (PIRES, 1989). No século XIX ocorre o reconhecimento da Medicina como profissão, os governos colonial, imperial e republicano consideram que para cuidar das doenças é necessário conhecimento especial, normatizado, estruturado, com intercâmbio entre América e Europa. A introdução do positivismo no Brasil no início do século $\mathrm{XX}$, tanto no ensino como na prática de saúde, representou uma ruptura com o conhecimento hegemônico, que era a metafísica, promovendo conforme Pires, (1989, p.81). "o desenvolvimento da pesquisa experimental, permitindo a demonstração do processo de transmissão das doenças e a aplicação de terapêuticas eficazes".

Tendo a Medicina à sua disposição uma tecnologia precisa, começa a desenvolver uma abordagem analítica, conforme expõe Collière (1989, p.123) reforçando "a separação do corpo e do espírito, apartando o doente da doença, parcelizando as regiões do corpo, os tecidos, as células, os núcleos... para identificar o normal do patológico”. È a doença que constitui objeto de investigação, o sujeito que vive a doença, torna-se menos importante.

A Medicina hipocrática nos fala de sintomas e de entidades nosológicas imutáveis e tenta estabelecer, como diz Caponi $(1995$, p.5) “condutas mais ou menos eficazes para prevenir maiores conseqüências e pata restaurar o equilíbrio perdido"

Durante toda esta explanação foi delineada a forma de imosição de poder com o nascimento do hospital e da Medicina. Nem sempre explicitados de forma clara, mais observáveis nos vários momentos históricos: um poder invisível que está tão visível. Inicialmente, o poder se instala pela exploração do corpo doente, no qual se forma sede silenciosa de saber e conhecimento médico. O pobre doente é hospitalizado, não visando à cura, mas sobretudo para segregá-lo, separá-lo do restante da população. Assim os ricos estariam protegidos das doenças. Para a assistência desse doente, desprotegido, pobre, afastado de sua família, recorria-se a pessoas religiosas, leigas e que dedicavam a vida ao cuidado mais espiritual do que material dos doentes. Essa mão de obra foi sendo substituída pelos médicos, com poder absoluto nas questões de saúde.

Cada vez mais o doente necessitava da prática caritativa dos hospitais e do saber médico; em troca ele dispunha seu corpo à exploração. A assistência que recebia transformava-se em saber do corpo médico. Percebe-se, hoje, que o exercício da profissão médica exerce o poder que foi propagado no passado. A instituição hospitalar coloca intermediários entre o cliente, médico e família, aumentando a ansiedade do doente. O médico coloca barreiras no relacionamento, por meio da linguagem. O médico não expõe claramente o que o doente necessita saber. Conforme Boltanski (1989), as explicações médicas variam de acordo com as classes sociais. O doente das classes menos favorecidas possui baixa 
instrução e portanto não está em condições de compreender a linguagem. Essa informação mínima concedida é uma forma autoritária do médico perante o doente. Além da linguagem pouco clara, o médico adota atitudes de infantilização do cliente. Os médicos agem para Boltanski $(1989$, p.56) como se "o deoente, por uma espécie de surdez, não pudesse ouvir as palavras cochichadas em voz alta".

A assimetria da relação médico-paciente cresce à medida que cresce a distância social. $\mathrm{O}$ doente representa o papel de objeto; o doente nu, deitado, imóvel e silencioso é o objeto de manipulação do médico, que está vestido, de pé e, com seus gestos livres, ordenando as condutas ao doente. Para Boltanski (1989), além da manipulação física, há a manipulação moral, como ridicularizar ou pôr em dúvida os sintomas, mostrar que o doente é pretencioso, apenas porque utilizou termos científicos, falar em voz alta, entre outras.

Pode-se imaginar por que as formas coercitivas de atuar sobre o corpo do doente são delineadas. São os vários tipos de poder que se exercem em níveis e pontos variados. O conceito dado por Roberto Machado, apud Focault (1992, p..X), é que " $o$ poder não é um objeto natural, uma coisa, é uma prática social”. O poder funciona como rede de dispositivos ou mecanismos a que ninguém escapa. Complementa ainda dizendo que o poder não existe, existem, sim, relações de poder, e este se exerce, se disputa. A citação do autor acima complementa o pensamento: A ação sobre o corpo, o adestramento do gesto, a regulação do comportamento, a normalização do prazer, a interpretação do discurso, com o objetivo de separar, comparar, tudo isso faz com que apareça pela primeira vez na história esta figura singular, individualizada - o homem - como produção do poder (p.XX).

Diante de todo esse contexto, encontra-se a Enfermagem que luta por firmar-se como ciência, tentando desfazer-se de uma prática ligada ao fazer, para tornar-se intelectual e científica. Historicamente, as normas médicas e masculinas influenciaram a prática profissional e o desenvolvimento educacional da Enfermagem.

\section{PODER E DESENVOLVIMENTO DA PRÁTICA DO CUIDADO E DA ENFERMAGEM}

A Enfermagem como profissão na Europa surge com Florence Nightingale em 1859 com a estruturação da escola de formação de enfermeiros administradores e prestadores de cuidados, modelo que se espalhou por todo o mundo ocidental. No Brasil a Enfermagem começa a organizar-se no século XIX com o treinamento de pessoal de Enfermagem para psiquiatria. Como profissão aparece 400 anos depois, no início do século $\mathrm{XX}$, com formação de enfermeiros para a saúde pública. (PIRES, 1989).

Os cuidados de manutenção da vida e os cuidados curativos, que surgem de descobertas empíricas, são substituídos pelos cuidados médicos, considerados os únicos científicos. Até o fim do século XIX, os processos de investigação e as terapêuticas médicas mantiveram-se sumárias e precárias. Com o aparecimento de tecnologias, o cuidado vai desaparecendo, os laços entre o homem-ambiente são negados. O objeto dos cuidados diz Collière (1989, p. 32), "torna-se isolado, parcelizado, fissurado, separa-se das dimensões sociais $e$ coletivas". O cuidar torna-se tratar doença.

Pires (1989) considera-se que a subordinação da equipe de Enfermagem ao médico está relacionada, em grande parte, ao exercício prático da profissão. O papel social de subordinação das mulheres se reproduz no espaço privado (família), como também no profissional. A historicidade da exclusão do papel feminino na sociedade contribui na reprodução das relações de poder de dominação-submissão até hoje presentes no setor saúde. A essa mulher excluída, oprimida lhe era permitido um trabalho caritativo junto aos doentes e o trabalho de parteira. Este não era considerado fenômeno médico, as mulheres parteiras ajudavam as outras porque tinham vivenciado a experiência da parturição. Era a mulher que devia exercer a prática dos partos, porque era a mulher a responsável em procriar os filhos e cuidar deles.

O valor social da prática de cuidados prestados pelas mulheres é reconhecido pelo conhecimento interiorizado, vivido por elas. Essas mulheres, afirma Collière (1989), além da experiência pessoal do parto, deveriam ser menopausadas. Assim, a avó, a sogra adquirem o status social reconhecido para ajudar as futuras mães. A parteira é reconhecida por toda a comunidade. Ao dominar a prática da parturição, as mulheres também desenvolveram o uso de plantas curativas como forma profilática de doenças. Mesmo sendo um saber não científico, o acúmulo de experiências dava à mulher cada vez mais poder, e isto significava uma ameaça ao poder espiritual da Igreja e ao médicos. Assim, começa a perseguição, a caça às bruxas. A Igreja apropriase do poder de discernir o que é bom ou mau para a alma e para o corpo, decide quais conhecimentos irá utilizar para tratar e limita as práticas de higiene. A prática dessa nova Medicina vai ser, durante muito tempo, exclusividade dos homens da Igreja.

As atividades de cunho profissional de assistência à parturiente no Brasil aparecem com a colonização. Os cursos de parteiras foram institucionalizados em 1832, quando se tornaram anexos às escolas de Medicina. O trabalho das parteiras passa a dar-se no hospital sob o controle médico. Esta institucionalização da prática tira das parteiras a autonomia e a vinculação com a comunidade, transformando-as em profissão auxiliar (Pires, 1989). A arte de partejar fica subordinada, portanto, à Medicina, cabendo a elas as atividades de scunho manual e devidamente delimitadas dentro da globalidade de assistência à parturiente, puérpera e recém-nascido. Collière (1989) cita que à medida que se reduzem os cuidados exercidos pelas mãos, aumenta o discurso, os conselhos, as recomendações baseados em princípios morais e religiosos.

Outro ponto importante é que o cuidado era dirigido aos sofredores, aos miseráveis. Era preciso haver uma degradação física ou social, alteração, perda da integridade, para que que os cuidados se tornassem necessários. Eram também dirigidos cuidados aos pobres, humildes, indigentes. As mulheres religiosas deviam servir - obedecer e estar apenas ligadas à oração, sem ter chances de adquirir maiores conhecimentos. O saber das mulheres era combatido, porque era ameaçador. No século XIX as noviças menos dotadas eram orientadas para o cuidado dos doentes; as mulheres incapazes de outros estudos fariam Enfermagem. Isto cria um grande vazio no conhecimento, que só é superado com as primeiras escolas de enfermeiras. As mulheres religiosas são 
o eixo de um sistema econômico de alto rendimento porque ao servir os pobres oferecem gratuitamente o seu serviço por toda a vida (Collière, 1989).

Como se percebe, desde o início do trabalho estruturado em saúde até o momento no Brasil, o médico é o centro de atenção; como gerenciador da assistência, delega funções parcelares aos outros trabalhadores sob seu controle. O trabalho de Enfermagem se originou da assistência caritativa e religiosa; inicia-se uma divisão de tarefas sob o controle de indivíduos superiores. AEnfermagem profissional nasce sob o modo de produção capitalista e se organiza dentro de seus preceitos, dentro do espaço hospitalar. A Enfermeira, para Loyola (1988, p.101)

"é submissa ao poder médico e esta dominação se legitima dentro do espaço disciplinar do hospital, onde através da própria disciplina, onde o corpo, o tempo e o espaço utilizados pelas enfermeiras são esquadrinhados". Nos dias de hoje, naquilo que envolve s relações de poder no hospital moderno entre médicos, enfermeiros e no poder microfísico que perpetua um "statu quo" de dominação do saber médico, a crítica que se fazé que conforme Loyola (1988, p.101), os enfermeiros "incorporam os aspectos sociais e religiosos de seu ideal profissional na figura abnegada e docilizada do anjo branco que serve com perfeição o Estado e o poder médico na medida em que eles se tornam corpos dóceis e disciplinados".

\section{CONSIDERAÇÕES}

Considero que esta análise histórica, que retrata o enfermeiro dentro da dominação médica vem expor, a preocupação em reorganizar a Enfermagem, livre deste poder.

A Enfermagem, para melhorar a sua condição, deve voltar-se para a sua razão de ser, que é o homem portador de doenças ou distúrbios, com o escopo de restabelecer a saúde, ou de administrar a enfermidade e morrer com dignidade. $\mathrm{O}$ poder hegemônico do médico já não tem razão de existir, cumpre que haja integração harmônica dos profissionais de saúde, no âmbito clínico e social e, ademais, em equilíbrio com a própria natureza.

Impõe-se hoje um olhar humanístico na prestação de cuidado. O cuidado considerado a essência da Enfermagem, é o enfoque da prática diária. É através dele que em contato com o cliente estabelece-se uma relação humanística. O poder disciplinar na Enfermagem tornar-se-á independente do saber médico, com a implementação de ações próprias do enfermeiro, propiciando modificações no cliente, utilizando os componentes do cuidado, reorganizando e orientando o cliente diante de situações que o expõe a risco.

O cuidado reconhece a presença do outro, é troca, doação, suporte, preocupação. $\mathrm{O}$ enfermeiro atua na compreensão das experiências vividas pelos clientes, torna o cuidado um fazer voltado ao respeito, dignidade, valorização do ser humano. $\mathrm{O}$ enfrentamento de estratégias humanísticas de cuidado dissipam o espaço de poder e possibilitam o desenvolvimento da profissão além do fazer técnico, gerando novo conhecimento de interações humanas para a ciência de Enfermagem. Buscar na complexidade do fenômeno cuidado o delineamento da profissão é meta a ser perseguida e imposta diante do contexto de relações de poder no espaço médico e de Enfermagem. A conquista da cientificidade e tecnologia, assim como, do aprimoramento do consumismo, perdeu de vista esse modo humano de cuidar e de se relacionar, facetas estruturais do homem.

A Enfermagem humanística engloba muito mais do que a competência técnica, engloba um modo de relacionar-se, um em favor do outro, seja do enfermeiro/cliente, seja do enfermeiro/ médico/membros da equipe. O ser e o fazer estão intimamente relacionados. Esta relação possibilita à Enfermagem a oportunidade para o desenvolvimento do ser humano, torna a existência uma coexistência humana. O processo de relações de poder dissipa-se através das inter-relações tronadas humanísticas. Este é um propósito da Enfermagem, fundamentar-se no fazer/ ser/relacionar-se de forma integral e humana. Este é o caminho, de transpor as questões de poder e hegemonias nas instituições de saúde.

\section{REFERÊNCIAS}

1. BOLTANSKI, Luc. As classes sociais e o corpo. 3.ed. Rio de Janeiro: Graal, 1989.

2. CAPONI, Sandra N.C. La ciencia e la condicion humana. Florianópolis: Curso de Doutorado em Filosofia de Enfermagem, UFSC, 1995. Mimeogragado.

3. Apontamentos de sala de aula da disciplina Filosofia da Ciência e Saúde II, ministrada no Curso de Doutorado em Filosofia de Enfermagem da Universidade Federal de Santa Catarina, 1995.

4. CARVALHO, Guido Ivan de; SANTOS, Lenir. Sistema Único de Saúde: comentários à Lei Orgânica de Saúde. São Paulo: Hucitec, 1992.

5. COLLIÈRE, Marie- Frasnçoise. Promover a vida: da prática das mulheres de virtude aos cuidados de Enfermagem. Lisboa: Printipo, 1989.

6. FOCAULT, Michel. Incorporación del hospital a la tecnologia moderna. In: __ La vida de los hombres infames. Madrid: La Piqueta, 1990. P.153-173.

7. Michel. Microfisica do poder. 10.ed. Rio de Janeiro: Graal, 1992

8. Michel. O nascimento da clínica. 4.ed. Rio de Janeiro: Forense Universitária, 1994.

9. LOYOLA, Cristina Maria Douat. Os dóceis corpos do hospital. 2.ed. Rio de Janeiro: UFRJ, 1988.

10. LUZ, Madel Therezinha. Natural, racional, social: razão médica e racionalidade científica moderna. Rio de Janeiro: Campus, 1988.

11. MELEIS, Afaf Ibrahim. Ser e tornar-se saudável: o âmago do conhecimento de enfermagem. Texto e Contexto, Florianópolis, v.1,n.2, p.36-55, jul/dez. 1992.

12. PIRES, Denise. Hegemonia médica na saúde e a Enfermagem. São Paulo : Cortez, 1989.

13. REED, Pamela G. A treatise on nursing Knowledge development for the 21 st century : beyond postmodernism. Adv. Nurs. Sci, Germantown, v. 17, n.3, p. 70-84, 1995.

14. ROSEN, George. Da polícia médica à medicina social. Rio de Janeiro : Graal, 1979.

15. SCLIAR, Moacyr. Do mágio ao social : a trajetória da saúde pública. Porto Alegre : L \& PM, 1987. 